\title{
Physician workload associated with do-not- resuscitate decision-making in intensive care units: an observational study using Cox proportional hazards analysis
}

Kuan-Han Lin', Shu-Chien Huang ${ }^{2}$, Chih-Hsien Wang ${ }^{2}$, Chau-Chung ${ }^{1,3}$, Tzong-Shinn Chu ${ }^{1,4}$ and Yen-Yuan Chen ${ }^{1 *}$ (D)

\begin{abstract}
Background: Physicians play a substantial role in facilitating communication regarding life-supporting treatment decision-making including do-not-resuscitate (DNR) in the intensive care units (ICU). Physician-related factors including gender, personal preferences to life-supporting treatment, and specialty have been found to affect the timing and selection of life-supporting treatment decision-making. This study aimed to examine the influence of physician workload on signing a DNR order in the ICUs.
\end{abstract}

Methods: This is retrospective observational study. The medical records of patients, admitted to the surgical ICUs for the first time between June 1, 2011 and December 31, 2013, were reviewed. We used a multivariate Cox proportional hazards model to examine the influence of the physician's workload on his/her writing a DNR order by adjusting for multiple factors. We then used Kaplan-Meier survival curves with log-rank test to compare the time from ICU admission to DNR orders written for patients for two groups of physicians based on the average number of patients each physician cared for per day during data collection period.

Results: The hazard of writing a DNR order by the attending physicians who cared for more than one patient per day significantly decreased by $41 \%$ as compared to the hazard of writing a DNR order by those caring for fewer than one patient (hazard ratio $=0.59,95 \% \mathrm{Cl} 0.39-0.89, P=.01$ ). In addition, the factors associated with writing a DNR order as determined by the Cox model were non-operative, cardiac failure/insufficiency diagnosis (hazard ratio $=1.71,95 \% \mathrm{Cl} 1$. $00-2.91, P=.05$ ) and the Therapeutic Intervention Scoring System score (hazard ratio $=1.02,95 \% \mathrm{Cl} 1.00-1.03, P=.03$ ). Physicians who cared for more than one patient per day were less likely to write a DNR order for their patients than those who cared for in average fewer than one patient per day (log-rank chi-square $=5.72, P=.02$ ).

Conclusions: Our findings highlight the need to take multidisciplinary actions for physicians with heavy workloads. Changes in the work environmental factors along with stress management programs to improve physicians' psychological well-being as well as the quality.

Keywords: Do-not-resuscitate, Workload, Life-supporting treatment, Intensive care

\footnotetext{
* Correspondence: chen.yenyuan@gmail.com

${ }^{1}$ Graduate Institute of Medical Education \& Bioethics, National Taiwan

University College of Medicine, \#1, Rd. Ren-Ai sec. 1, Taipei 10051, Taiwan

Full list of author information is available at the end of the article
}

(c) The Author(s). 2019 Open Access This article is distributed under the terms of the Creative Commons Attribution 4.0 International License (http://creativecommons.org/licenses/by/4.0/), which permits unrestricted use, distribution, and reproduction in any medium, provided you give appropriate credit to the original author(s) and the source, provide a link to the Creative Commons license, and indicate if changes were made. The Creative Commons Public Domain Dedication waiver (http://creativecommons.org/publicdomain/zero/1.0/) applies to the data made available in this article, unless otherwise stated. 


\section{Background}

In 1991, the Patient Self-Determination Act (PSDA) was passed in the United States to ensure that healthcare institutions informed patients of their rights to participate in their own medical decision-making and to complete advance directives [1]. Sensitive to the effect of the PSDA in the United States and the progress of hospice and palliative care, Taiwan became the first country in Asia to issue the "Hospice and Palliative Care Act" (HPCA) in 2000 [2]. This law gave patients with terminal illness, or whose death is inevitable in a short time as determined by attending physicians, the right to refuse unnecessary life-supporting treatment (LST) [3]. Furthermore, HPCA provided physicians a legal framework within which to sign do-not-resuscitate (DNR) orders in accordance with the will of patients.

In the past two decades, there has been plenty of studies on DNR orders and end-of-life care (EOLC) issues [4-8]. Many studies reported that increasing age, female gender, white race, single marital status, religious background, and the severity of clinical illness of patients are associated with writing a DNR order after admission to intensive care units (ICUs) [7-9]. In addition to patient-related factors, physician-related factors including gender, religious background, personal preferences to LSTs, and specialty also have been found to affect the timing and selection of LST decision-making [10-13]. Yuen et al. also reported that physicians' failure to provide adequate information also prevented patients or surrogates from making DNR decisions [14]. Accordingly, physicians play a substantial role in facilitating communication regarding LST decision-making including DNR.

For Americans during their last year of life, approximately one quarter to one half are admitted to an ICU $[15,16]$, and about one in five deaths occurs in the ICU [17]. ICU is not only a place for critical care and LST decision-making, but it is also a highly stressful working environment for physicians. Because of caring for critically ill patients in the ICU, physicians have to deal with more end-of-life decision-making and communicate with family members of the patients. Physicians working in the ICU are found to have higher levels of stress due to work demands [18]. A multicenter study focusing on physicians working in ICUs showed that discrepancy for job demand, conflict, the ethical decision-making of withdrawing LSTs were all potential stressors from the work environment [19]. Additionally, workload and time pressure were the main causes of emotional and interpersonal stresses among physicians in an ICU [20]. ICU physicians do not encounter many physically demanding activities, but they need to make a lot of LSTs decisions under considerable time pressure, which require ICU physicians' mental demands. Studies also showed that physicians who experienced overload from work had a high risk of psychological syndromes arising in response to the stressors on the job [21], and psychological syndromes were associated with negative attitudes and behaviors towards individual's work [22].

Although previous studies have found a variety of physician-related factors related to decision-making on a DNR order, studies examining the effect of physicians' workload on signing DNR orders for ICU patients are rarely conducted. Therefore, this study aimed to examine whether physician workload is associated with the decision made by patients to consent to a DNR order. We hypothesized that physician workload has an influence on the physician's writing of a DNR order.

\section{Methods}

\section{Setting}

This observational cohort study was performed in the surgical ICUs in a tertiary medical center with more than 2000 beds located at Northern Taiwan. The surgical ICUs were comprised of cardiovascular units (19 beds), a unit of thoracic surgery and neurosurgery (10 beds), general surgery units ( 27 beds), and a trauma unit ( 8 beds). The medical services for caring for the surgical ICU patients were shared by a team of physicians comprised of one board-certified surgical intensivist, and one or two house officer. The board-certified surgical intensivist was responsible for all medical care decisions, including discussing the appropriateness of DNR with patients and/or family members, writing a DNR order for the patient, and so on.

\section{Study design}

The medical records of the patients who met the following criteria were retrospectively reviewed: patients who were at the age of 20 or older; admitted to the surgical ICUs with a Therapeutic intervention scoring system (TISS) score; cared for by only one attending physician during their ICU stay; and admitted between June 2011 and December 2013. We collected patient-related variables including age, gender, religious background, education, marital status, working status, residence, the TISS score upon ICU admission, ICU admission diagnosis, the status of writing a DNR order, and the time duration from ICU admission to writing a DNR order. The attending physician-related variables such as age, gender and seniority were collected.

The TISS scoring system developed by Cullen et al. in 1974 [23] has become a widely accepted method for measuring the severity of clinical illness in ICUs $[24,25]$. The score ranges from 0 to 174 . Higher scores of TISS indicate more severe clinical illness and demand a higher number of therapeutic interventions and treatments. Based on the 50 APACHE II 
(Acute Physiology and Chronic Health Evaluation II) diagnostic categories [26], we collapsed the surgical ICU admission diagnosis into only 4 categories: (1) non-operative, cardiac failure/insufficiency; non-operative, others; (3) post-operative, major surgery; and (4) post-operative, others.

We estimated attending physician workload which was defined as the average number of patients each attending physician cared for per day. It was calculated as the sum of the patient-days of patients each attending physician cared for divided by the total number of days in data collection period. Based on the average number of patients they cared for per day, the attending physicians were divided into two workload groups: (1) those who cared for more than or equal to one patient per day; and (2) those who cared for less than one patient per day. The outcome variable in this study was the status of writing a DNR order. Furthermore, the incidence rate of writing a DNR order for each attending physician was calculated as the number of DNR decision divided by the sum of the patient-days for all patients each attending physician cared for.

\section{Statistical analysis}

Data analysis was conducted using the data of patients who had no missing data in all variables (Fig. 1). We used descriptive statistics to analyze the characteristics of patients and physicians. All data were expressed as the frequency (percentage) or mean \pm standard deviation. Continuous variables between the two groups of physicians were compared using Student's t-test. Categorical variables between the two groups were compared using Chi-square test. We used Pearson's correlation coefficient for examining the linear relationship between the incidence rate of writing a DNR order for each attending physician and the average number of patients each attending physician cared for per day.

Cox proportional hazards regression analysis was conducted to examine the influence of the attending physician's workload on his/her writing a DNR order by adjusting for the combined effect of multiple factors. Harrell's C-statistic was used to assess the discriminatory ability of the Cox proportional hazards regression model [27]. Kaplan-Meier survival curves of the two different attending physician workload groups were developed to compare the time from surgical ICU admission to writing a DNR order for patients. A DNR order written was considered as an "event" and the ICU discharge was considered as "censored" in the survival analyses. Differences between the two Kaplan-Meier curves were tested using log rank tests.

A $p$ value of less than or equal to 0.05 was considered statistically significant. All statistical analyses were conducted with SAS 9.4 (SAS Institute Inc., Cary, NC,

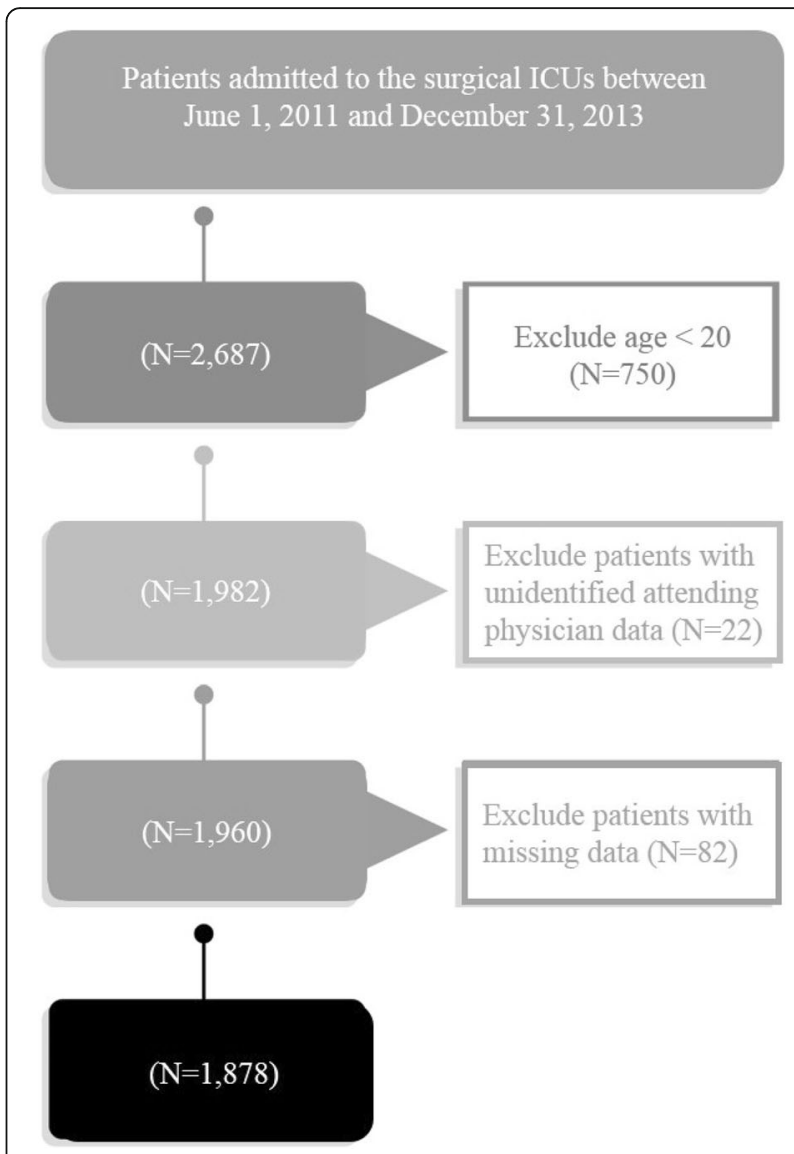

Fig. 1 Participant selection

USA). This study was approved by the Research Ethics Committee (REC) in National Taiwan University Hospital (20140308RINC).

\section{Results}

A total of 1878 patients were enrolled. The majority of the participants in this study were males $(67.41 \%)$ and the average age was 61.72 years (standard deviation $=15.11$ ). . Most of them were married $(76.73 \%)$ and had an education level of high school or below (60.17\%). Moreover, $37.91 \%$ of the participants were working fulltime, and $5.22 \%$ were from rural areas. The mean TISS score of the 1878 participants was 32.01 (standard deviation $=10.80$ ). Approximately $48 \%$ of patients had the admission diagnosis of "non-operative, cardiac failure/insufficiency". The average length of stay in surgical ICU was 6.43 days (standard deviation $=13.23$ ). Among the 1878 patients, 120 (6.4\%) had a DNR order written during their surgical ICU stay. The average length of time from ICU admission to writing a DNR order was 20.31 days $($ standard deviation $=19.31)$.

All 15 attending physicians who cared for 1878 patients were male, and their average age upon the beginning of data collection period was 50.25 years (standard deviation $=7.51$ ). The total number of patients each 
physician cared for during data collection period ranged from 1 to 498. Figure 2 shows the total number of patient-days for each attending physician during data collection period, and the average number of patients each attending physician cared for per day during data collection period. Figure 3 shows the incidence rate of writing a DNR order for each attending physician, ranging from 0 to $2.95 \%$. Furthermore, the scatter plot for the relationship between the average number of patients each attending physician cared for per day and the incidence rate of writing a DNR order for each attending physician was shown in Fig. 4, and the Pearson's correlation coefficient between them was $0.06(p=0.85)$.

When compared to the patients cared for by the attending physician with less workload, the patients cared for by the attending physician with heavier workload were married $(p<0.01)$, more likely to have an education level of college or above $(p=0.01)$, admitted to the surgical ICU with a higher TISS score $(p<0.01)$, and more likely to have the admission diagnosis of "non-operative, cardiac failure/insufficiency" $(p<0.01)$ (Table 1$)$.

The results of the multivariate Cox proportional hazards model are shown in Table 2. All patient-related variables were put into the model for adjustment. Regarding to the attending physician-related variables, since all attending physicians were male, and their age was highly correlated with their seniority, only physician's age and workload were included in the model. After adjusting for the potential confounding variables, the hazard of writing a DNR order for their patients cared for by the attending physicians with a heavier workload significantly decreased by $41 \%$ as compared to the hazard of writing a DNR order for their patients cared for by the attending physicians with less workload (hazard ratio $=0.59, p=0.01$ ). In addition, the factors associated with writing a DNR order as determined by the Cox model were non-operative, cardiac failure/insufficiency diagnosis (hazard ratio $=1.71, p=0.05$ ) and the TISS score (hazard ratio $=1.02, p=0.03$ ). Harrell's $C$-statistic for the model was 0.73 , indicating an acceptable discrimination.

We summarized the significant difference between the two groups of attending physicians' workloads using Kaplan-Meier analysis in Fig. 5. Attending physicians who cared for greater than or equal to one patient per day during the data collection period were less likely to write a DNR order for their patients than those who cared for less than one patient per day (log-rank chi-square $=5.72, p=0.02$ ).

\section{Discussion}

\section{Main outcomes}

This study examined the influence of attending physician workload on signing a DNR order in ICUs. We

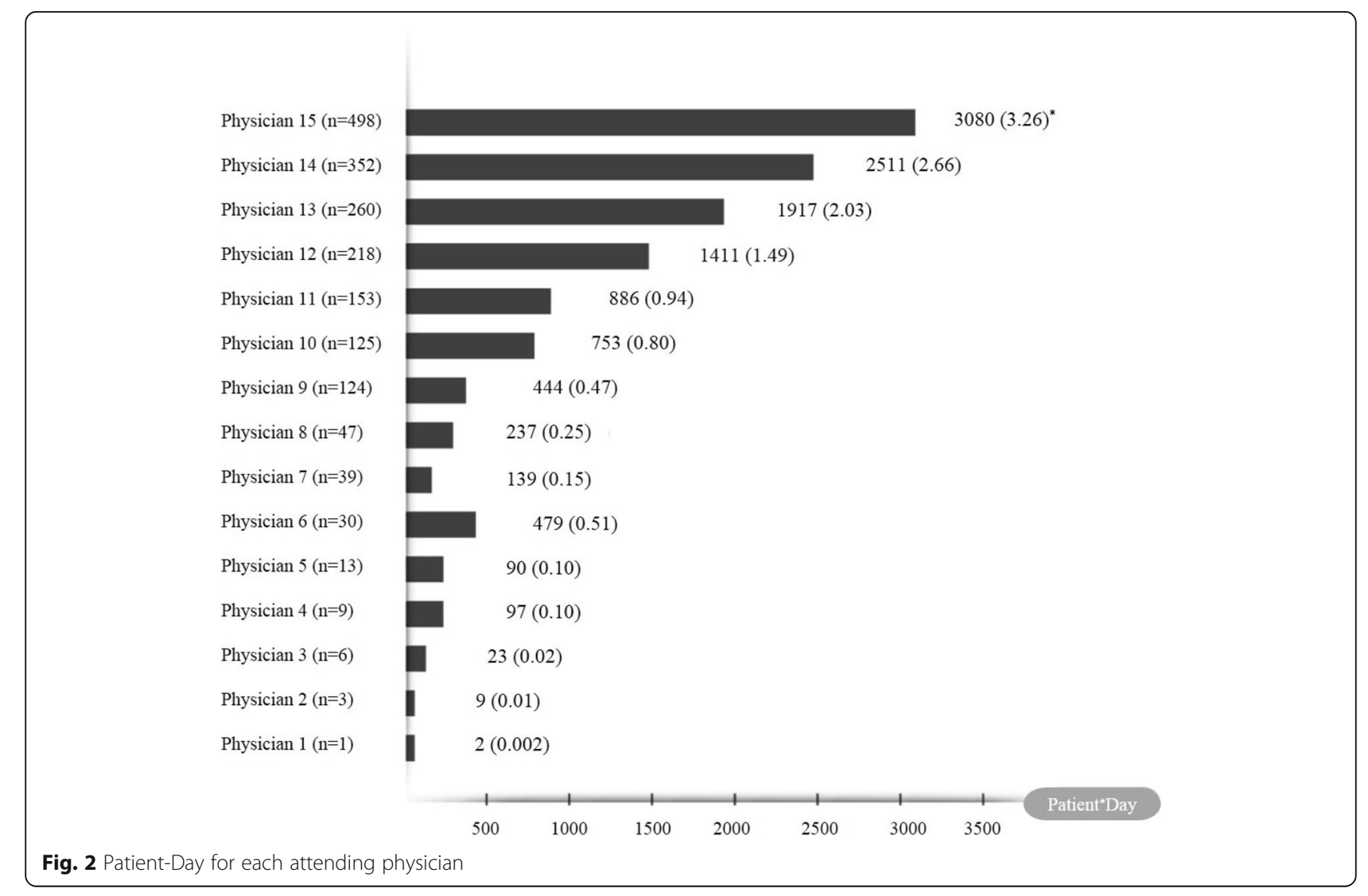




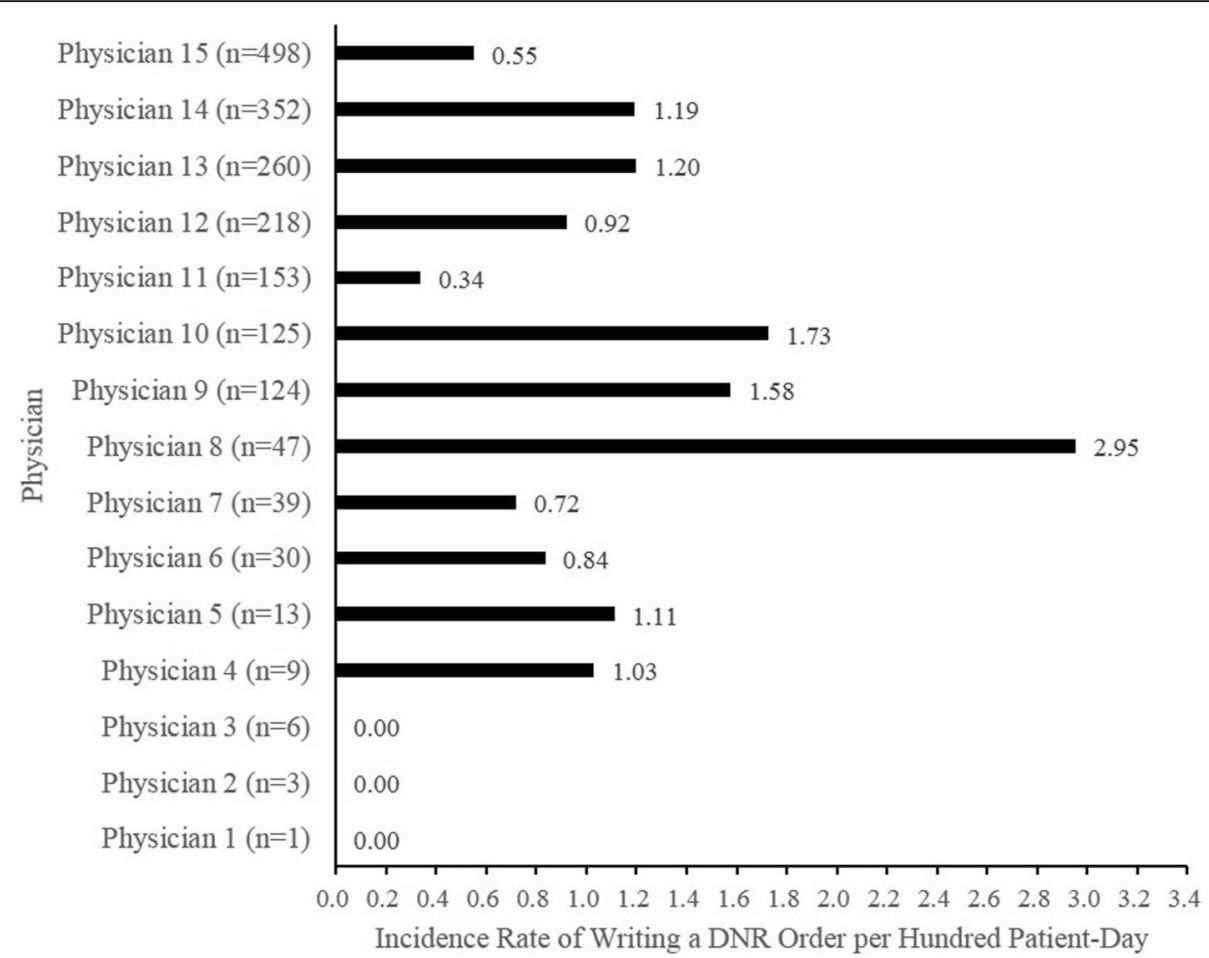

Fig. 3 Incidence rate for writing a DNR order for each attending physician

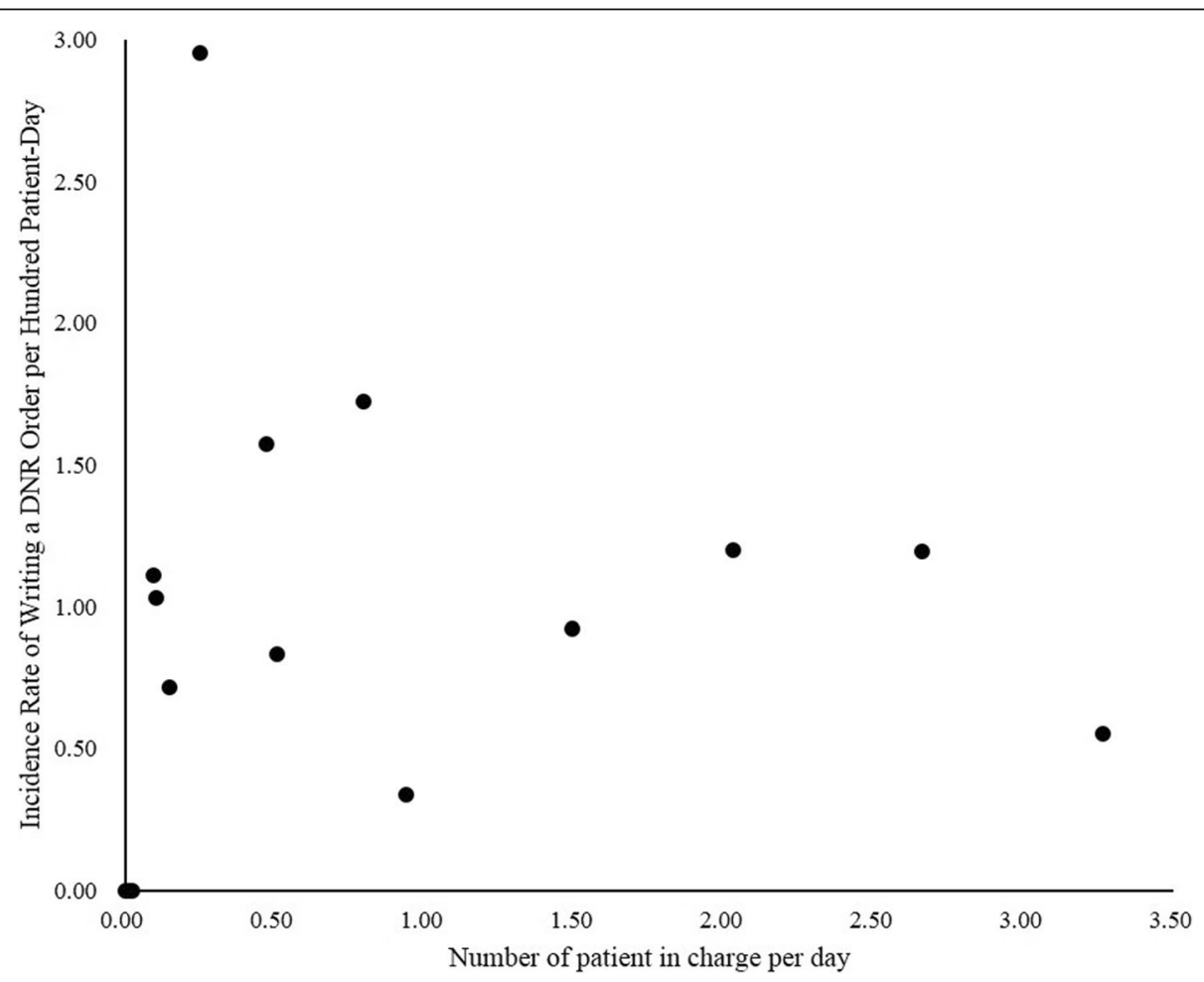

Fig. 4 Scatterplot for the relationship between the number of patients in charge and incidence rate of writing a DNR order for each attending physician 
Table 1 Characteristics of patients in different physician workload groups

\begin{tabular}{|c|c|c|c|}
\hline & \multicolumn{2}{|c|}{ Physician workload (the number of patients physician cared for per day) } & \multirow{3}{*}{$\begin{array}{l}P \\
\text { value }\end{array}$} \\
\hline & $\geqq 1(n=1328)$ & $<1(n=550)$ & \\
\hline & N (\%) & N (\%) & \\
\hline Gender & & & 0.98 \\
\hline Male & $895(67.40)$ & $371(67.46)$ & \\
\hline Female & $433(32.60)$ & $179(32.54)$ & \\
\hline Age, years (Mean $\pm S D$ ) & $61.91 \pm 14.50$ & $61.26 \pm 16.48$ & 0.42 \\
\hline Religion & & & 0.19 \\
\hline Others & $633(47.67)$ & $286(52.00)$ & \\
\hline Buddhist/Daoist & $614(46.23)$ & $237(43.09)$ & \\
\hline Christian/Catholic & $81(6.10)$ & $27(4.91)$ & \\
\hline Education, years & & & 0.01 \\
\hline$>12$ & $425(32.00)$ & $142(25.82)$ & \\
\hline $1-12$ & $771(58.06)$ & $359(65.27)$ & \\
\hline 0 & $132(9.94)$ & $49(8.91)$ & \\
\hline Marital status & & & $<0.01$ \\
\hline Married & $1053(79.29)$ & $388(70.54)$ & \\
\hline Others & $275(20.71)$ & $162(29.46)$ & \\
\hline Working fulltime & & & 0.87 \\
\hline Yes & $505(38.03)$ & $207(37.64)$ & \\
\hline No & $823(61.97)$ & $343(62.36)$ & \\
\hline Residence & & & 0.33 \\
\hline Rural area & $65(4.90)$ & $33(6.00)$ & \\
\hline Urban area & $1263(95.10)$ & $517(94.00)$ & \\
\hline Diagnosis & & & $<0.01$ \\
\hline Non-operative, cardiac failure/insufficiency & $672(50.60)$ & $230(41.82)$ & \\
\hline Non-operative, others & $58(4.37)$ & $52(9.45)$ & \\
\hline Post-operative, major surgery & $412(31.02)$ & $131(23.82)$ & \\
\hline Post-operative others & $186(14.01)$ & $137(24.91)$ & \\
\hline TISS (Mean \pm SD) & $32.74 \pm 10.13$ & $30.25 \pm 12.10$ & $<0.01$ \\
\hline Length of surgical ICU stay, days (Mean \pm SD) & $6.72 \pm 11.13$ & $5.74 \pm 17.27$ & 0.15 \\
\hline
\end{tabular}

Abbreviations: DNR do-not-resuscitate, TISS Therapeutic Intervention Scoring System, ICU Intensive care unit, SD Standard deviation

found that, after adjusting for other confounding variables, the attending physician with a heavier workload as indicated by the average number of patients he/she cared for per day were less likely to write a DNR order for his/her patients.

\section{Generalizability}

In this study, we retrospectively reviewed 1878 patients' medical records. Among them, $6.4 \%$ of the patients had a DNR order written during their surgical ICU stay. The result was similar to those reported in the literature. Zimmerman et al. reported that the rate of DNR orders ranged from 0.4 to $13.5 \%$ in ICU admissions at 13 hospitals [28]. According to a multicenter study conducted in 42 medical centers in the United States, $9 \%$ of the
17,440 ICU patients had DNR orders written [29]. Nathan et al., based on the data derived from the National Study on the Costs and Outcomes of Trauma, found that across the ICUs of 68 medical centers, $7 \%$ of the 6765 patients had a DNR order [8]. Hence, the percentage of patients with DNR orders in our study was similar to several prior studies.

In addition, the result of this study showed that an admission diagnosis of "non-operative, cardiac failure/insufficiency" and the severity of clinical illness as indicated by the TISS scores were positively associated with writing a DNR order. Our findings were consistent with several prior studies [8, 30,31]. Phillips et al., using the data derived from the SUPPORT (Study to Understand Prognoses and Preferences for Outcomes and 
Table 2 The multivariate Cox proportional hazards model of writing a DNR order

\begin{tabular}{|c|c|c|c|c|}
\hline & \multirow{2}{*}{$\begin{array}{l}\text { Hazard } \\
\text { Ratio* }^{*}\end{array}$} & \multicolumn{2}{|c|}{ 95\% Cl for Hazard Ratio } & \multirow[t]{2}{*}{$p$ value } \\
\hline & & Lower & Upper & \\
\hline \multicolumn{5}{|l|}{ Gender } \\
\hline Male & 0.93 & 0.60 & 1.44 & 0.75 \\
\hline Female & 1.00 & - & - & - \\
\hline Age, years & 1.01 & 0.99 & 1.03 & 0.14 \\
\hline \multicolumn{5}{|l|}{ Religion } \\
\hline Others & 0.62 & 0.29 & 1.32 & 0.21 \\
\hline Buddhist/Daoist & 0.63 & 0.29 & 1.35 & 0.23 \\
\hline Christian/Catholic & 1.00 & - & - & - \\
\hline \multicolumn{5}{|l|}{ Education, years } \\
\hline$>12$ & 0.79 & 0.37 & 1.67 & 0.54 \\
\hline $1-12$ & 0.71 & 0.37 & 1.34 & 0.29 \\
\hline 0 & 1.00 & - & - & - \\
\hline \multicolumn{5}{|l|}{ Marital status } \\
\hline Married & 0.84 & 0.55 & 1.28 & 0.41 \\
\hline Others & 1.00 & - & - & - \\
\hline \multicolumn{5}{|l|}{ Working fulltime } \\
\hline Yes & 0.77 & 0.47 & 1.25 & 0.29 \\
\hline No & 1.00 & - & - & - \\
\hline \multicolumn{5}{|l|}{ Residence } \\
\hline Rural area & 1.96 & 0.93 & 4.14 & 0.08 \\
\hline Urban area & 1.00 & - & - & - \\
\hline \multicolumn{5}{|l|}{ Diagnosis } \\
\hline Non-operative, cardiac failure/insufficiency & 1.71 & 1.00 & 2.91 & 0.05 \\
\hline Non-operative, others & 2.30 & 0.87 & 6.06 & 0.09 \\
\hline Post-operative, major surgery & 0.82 & 0.40 & 1.65 & 0.57 \\
\hline Post-operative others & 1.00 & - & - & - \\
\hline TISS & 1.02 & 1.00 & 1.03 & 0.03 \\
\hline \multicolumn{5}{|c|}{ Physician workload (number of patients physician cared per day) } \\
\hline$\geqq 1$ & 0.59 & 0.39 & 0.89 & 0.01 \\
\hline$<1$ & 1.00 & - & - & - \\
\hline Physician age, years & 0.99 & 0.97 & 1.02 & 0.54 \\
\hline
\end{tabular}

Abbreviations: TISS Therapeutic Intervention Scoring System, Cl confidence interval ${ }^{*}$ Adjusted for all above variables

Risks of Treatments) project, found that the diagnosis and severity of clinical illness upon ICU admissions were associated with a DNR order in patients hospitalized with serious illnesses [31].

As indicated by the percentage of writing a DNR order, the ICU admission diagnosis, and the severity of clinical illness, the generalizability of the results of this study may be as good as several prior studies in the literature.

\section{Physician's age and do-not-resuscitate orders}

In this study, the age of the physician was not significantly associated with writing DNR orders for patients.
This finding was in line with the result reported by Giannini et al. that physician age did not have significant influence on the end-of-life treatment decisions [32]. In contrast, some studies found that physician age was a significant factor associated with treatment decisions. Alemayehu et al. found that older physicians were more likely to choose less vigorous treatments [33]. On the other hand, Christakis and Asch found that younger physicians were more strongly in favor of withdrawing LSTs [34]. In spite of the fact that physicians can influence LST decision-making, the influence of physician age on LST decision-making remains controversial. 


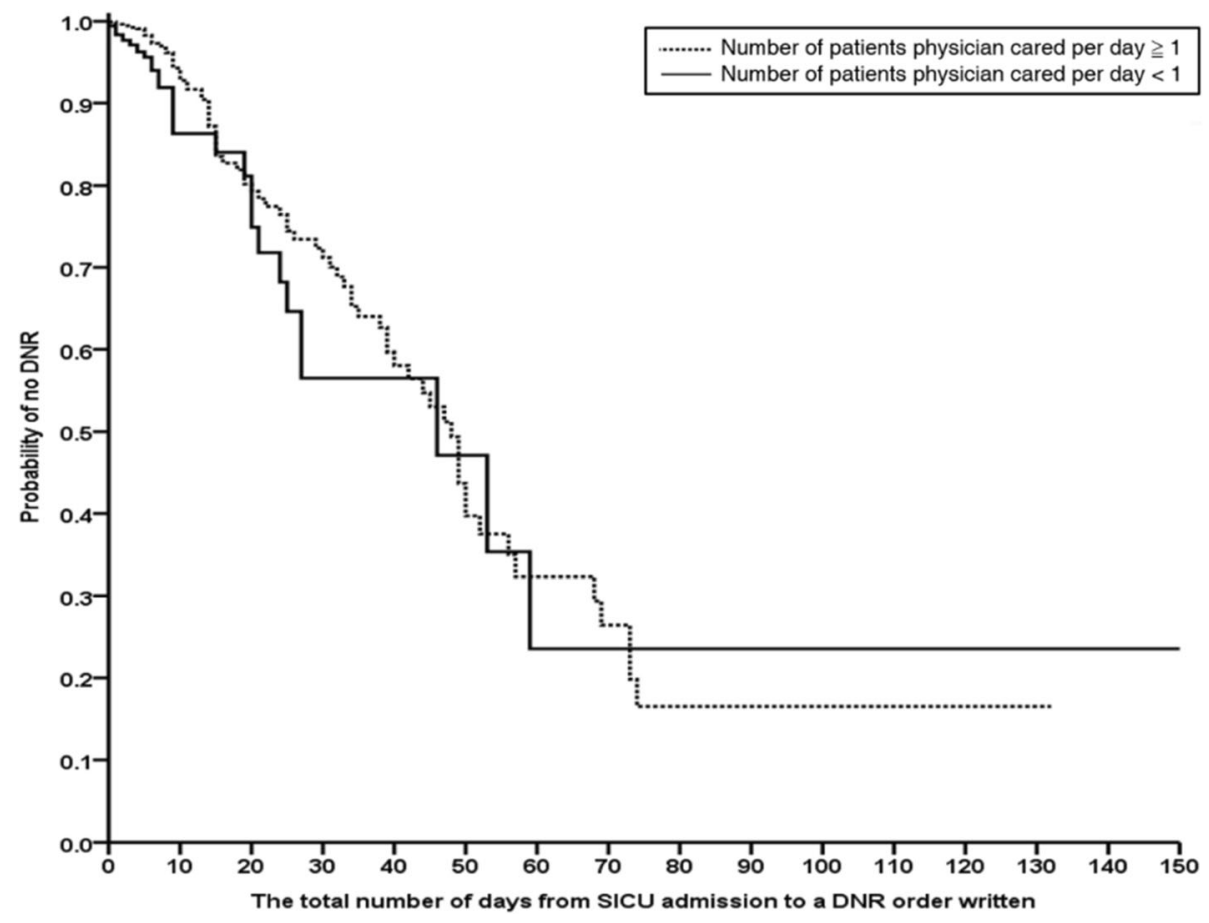

Fig. 5 Probability of writing a DNR order

\section{Physicians' workload and do-not-resuscitate orders}

We found that the physicians who were stressed with heavier workloads as indicated by caring for more patients were significantly associated with a lower likelihood of writing a DNR order for their patients. Several possibilities may account for this result:

Firstly, the physicians' lack of time to carefully deliberate the appropriateness of writing a DNR order for the patient may relate to this finding. Since most DNR discussions are prompted by physicians, whether they bring the DNR discussion up can significantly influence patients'/surrogates' DNR decisions [35, 36]. Physicians who were tasked with caring for a higher volume of patients per day might have had less time to carefully deliberate whether or not cardiopulmonary resuscitation is useful or harmful. As a result, the physicians were less likely to bring the DNR discussion up, and therefore the patients/surrogates were less likely to consent to a DNR order.

Secondly, the physicians' burnout-associated negative attitudes towards patients may account for this finding. Heavy workload was the main cause of high levels of burnout symptoms among ICU physicians [20, 37]. Since burnout is described as a prolonged response to chronic emotional and interpersonal stress on the job [38], the physicians who were unable to cope with the stress from heavier workloads were more likely to be emotionally and interpersonally exhausted, and developed negative attitudes toward their patients [39]. The physicians, therefore, would be reluctant to visit patients/surrogates and initiate the DNR discussion.

Thirdly, physicians who were tasked with a heavier workload were associated with poor quality of communication with patients/surrogates [40], and were also negatively associated with empathy [41]. For a physician with heavier workload providing intensive and critical care to his/her patients, communicating with the patients/surrogates about LSTs and decision-making such as consenting to a DNR order may not be a compelling task and of low priority. The physicians lacking empathy and a good quality of communication with patients/surrogates were less likely to attempt to initiate the DNR discussion with patients/surrogates [42], or to bring up a successful DNR discussion to achieve the goal of medical care [43]. Therefore, patients/surrogates would be less likely to consent to a DNR order.

Specific education training on EOLC which focuses on issues of DNR orders is needed to give physicians, especially those who are caring for more patients, the confidence and skill to communicate positively with patients/ surrogates. Moreover, it is not only front line healthcare workers who need additional training but also healthcare workers not on the frontline. In ICU, since attending physicians serving on the frontline may be exposed to a high level of stress with heavier workloads and challenges [44], a DNR discussion with patients/surrogates is encouraged to be initiated by well-trained healthcare workers serving non-frontline positions [45]. 
Since excessive workloads may prevent physicians from having sufficient time to assess patients, and may decrease quality of patient care [46], stress management training programs in reducing work stress and risk of psychological syndromes due to high workload are highly suggested for physicians. Person-directed (e.g. cognitive behavioral therapy, relaxation, music making, massage, and so on) and work-directed (e.g. attitude change and communication, support from colleagues, participatory problem solving and decision-making, changes in work organization, and so on) intervention strategies for preventing work stress in healthcare workers have been proposed in the previous studies [47]. Hence, for those physicians who suffered high workloads, it is useful to apply suitable intervention strategies as early as possible for promoting physicians' psychological health as well as encouraging the DNR discussion with patients.

\section{Strengths and limitations}

We reported that attending physician workload indicated by the average number of patients he/she cared for per day was significantly associated with writing a DNR order, which was never examined in the past. However, there are some limitations in this study:

Firstly, our findings may not reflect the situation existing in other medical institutions. In addition, this study was conducted in surgical ICUs. It may be possible to have different findings if examining the same issue in medical ICUs. In addition, since attitudes and perspectives about DNR may vary in different places and healthcare institutions [48], this study's results are closely related to the most current and comprehensive interpretation of DNR in Taiwan.

Secondly, some insufficiencies in methods might hurt the outcomes of this study. For example, some potential confounding variables, e.g. unmeasured physicians' variables, were not included in the multivariate Cox proportional hazards regression model. In addition, although the multivariate Cox proportional hazards regression model is most popular for survival data analysis, there may be concerns that our results still suffer from ecological bias.

Thirdly, the DNR order was not always consented to by the patient. Decisions to consent to DNR orders in Taiwan are usually made by family members [49]. This study was limited by the omissions of information that some DNR orders may have been consented to by surrogate decision-makers. However, the omissions did not obscure the value of our study results because this was not usually considered in prior studies on DNR.

Fourthly, the average number of patients an attending physician cared for per day was used as an indicator of workload in this study. However, the average number of patients an attending physician cared for per day may not comprehensively represent the workload. For example, some physicians caring for a fewer number of patients may need to do administrative or research tasks as well. Nonetheless, due to a lack of a well-developed and widely-recognized way to quantify the administrative and research workload, the average number of patients a physician cared for per day and each physician's total number of patient-days may still have academic merit to provide sufficient information on workload. In addition, patients usually require the most work when they arrive at ICUs and when they leave ICUs. Simply seeing the workload by taking the average number of patients cared for a day may be of concerns.

\section{Conclusion}

Our study reported that attending physicians who suffered from heavier workloads as indicated by caring for more patients per day were less likely to write a DNR order. Our findings highlight the need to take multidisciplinary actions for attending physicians suffering from heavy workloads. Changes in the work environmental factors along with stress management programs to improve physicians' psychological well-being as well as the quality of care provided to patients are warranted. Future studies should focus on examining the association between physician workload and the likelihood of writing a DNR order for patients through qualitative and quantitative research. Even if physicians are stressed with heavy workloads, educational interventions are still important and should be executed to facilitate the discussion between medical professionals/other healthcare team members and patients/family members about goals of care and preferences regarding resuscitation.

\section{Abbreviations}

APACHE II: Acute Physiology and Chronic Health Evaluation II; DNR: Do-notresuscitate; EOLC: End-of-life care; ICU: Intensive care units; LST: lifeSupporting treatment; PSDA: Patient Self-Determination Act; REC: Research Ethics Committee; SUPPORT: Study to Understand Prognoses and Preferences for Outcomes and Risks of Treatments; TISS: Therapeutic Intervention Scoring System

\section{Acknowledgements}

None.

\section{Funding}

This study was supported by the research grants from Taiwan Ministry of Science and Technology (MOST 103-2511-S-002-008-MY5) and National Taiwan University Hospital (NTUH 106-S3553). The funding agencies only provided financial support to this study and did not have any involvement in data collection, data analysis, and data interpretation.

\section{Availability of data and materials}

Drs. Yen-Yuan Chen and Kuan-Han Lin have full access to all the data in this study and all authors take complete responsibility for the integrity of the data and the accuracy of the data analysis. Dataset for this study can be requested by qualified researchers to Drs. Yen-Yuan Chen and Kuan-Han Lin.

\section{Authors' contributions}

$\mathrm{KL}$ carried out literature review, study design, statistical analyses, manuscript drafting, and manuscript editing. SH participated in study design, statistical 
analyses, and manuscript editing. CW (Wang) performed literature review and data collection. CW (Wu) carried out study design and manuscript editing. TC edited manuscript. YC conducted literature review, study design, manuscript drafting, manuscript editing, and funding support. All authors read and approved the final manuscript.

\section{Ethics approval and consent to participate}

This study was approved by the Research Ethics Committee (REC) in National Taiwan University Hospital (20140308RINC). This is a retrospective, medical records review study, and the participants' consents to join this study were waived.

\section{Consent for publication}

This study does not contain any individual person's data in any form.

\section{Competing interests}

The authors declare that they have no competing interests.

\section{Publisher's Note}

Springer Nature remains neutral with regard to jurisdictional claims in published maps and institutional affiliations.

\section{Author details}

${ }^{1}$ Graduate Institute of Medical Education \& Bioethics, National Taiwan University College of Medicine, \#1, Rd. Ren-Ai sec. 1, Taipei 10051, Taiwan. 2Department of Surgery, National Taiwan University Hospital, \#7, Rd. Chong-Shang S, Taipei 10002, Taiwan. 3 Department of Internal Medicine, National Taiwan University Hospital, \#7, Rd. Chong-Shang S, Taipei 10002 Taiwan. ${ }^{4}$ Department of Medical Education, National Taiwan University Hospital, \#7, Rd. Chong-Shang S, Taipei 10002, Taiwan.

\section{Received: 11 September 2017 Accepted: 22 February 2019}

\section{Published online: 01 March 2019}

\section{References}

1. Teno JM, Branco KJ, Mor V, Phillips CD, Hawes C, Morris J, et al. Changes in advance care planning in nursing homes before and after the patient selfdetermination act: report of a 10-state survey. J Am Geriatr Soc. 1997;45(8): 939-44.

2. Ministry of Justice. Laws and regulations database of the Ministry of Justice. Taipei, Taiwan: Working Group of the Ministry of Justice; 2004. Available at https://law.moj.gov.tw/LawClass/LawAll.aspx?pcode=L0020066.(Accessed on July 7, 2017)

3. Chen RC. The Spirit of humanism in terminal care: Taiwan experience. Open Area Studies Journal. 2009;2:7-11.

4. Chen YY, Chen YS, Chu TS, Lin KH, Wu CC. Further deliberating the relationship between do-not-resuscitate and the increased risk of death. Sci Rep. 2016;6:23182

5. Chen YY, Gordon NH, Connors AF Jr, Garland A, Chu TS, Youngner SJ. The outcome of patients with 2 different protocols of do-not-resuscitate orders: an observational cohort study. Medicine (Baltimore). 2015;94(42):e1789.

6. Hakim RB, Teno JM, Harrell FE Jr, Knaus WA, Wenger N, Phillips RS, et al. Factors associated with do-not-resuscitate orders: patients' preferences, prognoses, and physicians' judgments. SUPPORT investigators. Study to understand prognoses and preferences for outcomes and risks of treatment. Ann Intern Med. 1996;125(4):284-93.

7. Lin KH, Chen YS, Chou NK, Huang SJ, Wu CC, Chen YY. The associations between the religious background, social supports, and do-not-resuscitate orders in Taiwan: an observational study. Medicine (Baltimore). 2016;95(3): e2571.

8. Nathens AB, Rivara FP, Wang J, Mackenzie EJ, Jurkovich GJ. Variation in the rates of do not resuscitate orders after major trauma and the impact of intensive care unit environment. J Trauma. 2008:64(1):81-8 discussion 8-91.

9. Chang Y, Huang CF, Lin CC. Do-not-resuscitate orders for critically ill patients in intensive care. Nurs Ethics. 2010:17(4):445-55.

10. Frost DW, Cook DJ, Heyland DK, Fowler RA. Patient and healthcare professional factors influencing end-of-life decision-making during critical illness: a systematic review. Crit Care Med. 2011;39(5):1174-89.

11. Garland A, Connors AF. Physicians' influence over decisions to forego life support. J Palliat Med. 2007;10(6):1298-305.
12. Phua J, Joynt GM, Nishimura M, Deng $Y$, Myatra SN, Chan $Y H$, et al. Withholding and withdrawal of life-sustaining treatments in intensive care units in Asia. JAMA Intern Med. 2015;175(3):363-71.

13. Schenker $Y$, Tiver GA, Hong SY, White DB. Association between physicians beliefs and the option of comfort care for critically ill patients. Intensive Care Med. 2012;38(10):1607-15.

14. Yuen JK, Reid MC, Fetters MD. Hospital do-not-resuscitate orders: why they have failed and how to fix them. J Gen Intern Med. 2011;26(7):791-7.

15. Barnato $A E$, McClellan MB, Kagay CR, Garber AM. Trends in inpatient treatment intensity among Medicare beneficiaries at the end of life. Health Serv Res. 2004;39(2):363-76.

16. Wennberg JE, Cooper MM, Birkmeyer J. The quality of medical care in the United States: a report on the Medicare program. The Dartmouth atlas of health care. 1999;1999.

17. Angus DC, Barnato AE, Linde-Zwirble WT, Weissfeld LA, Watson RS, Rickert T, et al. Use of intensive care at the end of life in the United States: an epidemiologic study. Crit Care Med. 2004;32(3):638-43.

18. Guntupalli K, Fromm RE Jr. Burnout in the internist-intensivist. Intensive Care Med. 1996:22(7):625-30.

19. Teixeira C, Ribeiro O, Fonseca Aó M, Carvalho AS. Burnout in intensive care units a consideration of the possible prevalence and frequency of new risk factors: a descriptive correlational multicentre study. BMC Anesthesiol. 2013;13:38.

20. Schaufeli WB. Burnout in health care. Handbook of human factors and ergonomics in health care and patient safety 2007:217-232.

21. Embriaco N, Azoulay E, Barrau K, Kentish N, Pochard F, Loundou A, et al. High level of burnout in intensivists: prevalence and associated factors. Am J Resp Crit Care Med. 2007;175(7):686-92.

22. Maslach C, Wilmar B, Schaufeli WB. Chapter 1, Historical and conceptual development of burnout. In Book: Professional Burnout: Recent Developments in Theory and Research, 1st edition, 1993:1-16.

23. Cullen DJ, Civetta JM, Briggs BA, Ferrara LC. Therapeutic intervention scoring system: a method for quantitative comparison of patient care. Crit Care Med. 1974;2(2):57-60

24. Bams $J$, Miranda DR. Outcome and costs of intensive care. A follow-up study on 238 ICU-patients. Intensive Care Med. 1985;11(5):234-41.

25. Cullen DJ. Results and costs of intensive care. Anesthesiology. 1977:47(2): 203-16

26. Knaus WA, Draper EA, Wagner DP, Zimmerman JE. APACHE II: a severity of disease classification system. Crit Care Med. 1985;13(10):818-29.

27. Harrell F. Regression modeling strategies: with applications to linear models, logistic and ordinal regression, and survival analysis: Springer; 2015.

28. Zimmerman JE, Knaus WA, Sharpe SM, Anderson AS, Draper EA, Wagner DP. The use and implications of do not resuscitate orders in intensive care units. JAMA. 1986;255(3):351-6.

29. Jayes RL, Zimmerman JE, Wagner DP, Draper EA, Knaus WA. Do-notresuscitate orders in intensive care units Current practices and recent changes. JAMA. 1993:270(18):2213-7.

30. Huang CT, Chuang YC, Tsai YJ, Ko WJ, Yu CJ. High mortality in severe sepsis and septic shock patients with do-not-resuscitate Oorders in East Asia. PLoS One. 2016;11(7)

31. Phillips RS, Wenger NS, Teno J, Oye RK, Youngner S, Califf R, et al. Choices of seriously ill patients about cardiopulmonary resuscitation: correlates and outcomes. SUPPORT investigators. Study to understand prognoses and preferences for outcomes and risks of treatments. Am J Med. 1996;100(2): 128-37.

32. Giannini A, Pessina A, Tacchi EM. End-of-life decisions in intensive care units: attitudes of physicians in an Italian urban setting. Intensive Care Med. 2003; 29(11):1902-10.

33. Alemayehu E, Molloy DW, Guyatt GH, Singer J, Penington G, Basile J, et al. Variability in physicians' decisions on caring for chronically ill elderly patients: an international study. CMAJ. 1991;144(9):1133-8.

34. Christakis NA, Asch DA. Physician characteristics associated with decisions to withdraw life support. Am J Public Health. 1995;85(3):367-72.

35. Ahmed N, Lobchuk M, Hunter WM, Johnston P, Nugent Z, Sharma A, et al. How, when and where to discuss do not resuscitate: a prospective study to compare the perceptions and preferences of patients, caregivers, and health care providers in a multidisciplinary lung cancer clinic. Cureus. 2015; 7(3):e257.

36. Tilden VP, Tolle SW, Garland MJ, Nelson CA. Decisions about life-sustaining treatment Impact of physicians' behaviors on the family. Arch Intern Med. 1995; 155(6):633-8 
37. Coomber S, Todd C, Park G, Baxter P, Firth-Cozens J, Shore S. Stress in UK intensive care unit doctors. Br J Anaesth. 2002;89(6):873-81.

38. Maslach C, Schaufeli WB, Leiter MP. Job burnout. Annu Rev Psychol. 2001;52: 397-422.

39. Halbesleben JR, Rathert C. Linking physician burnout and patient outcomes: exploring the dyadic relationship between physicians and patients. Health Care Manag Rev. 2008;33(1):29-39.

40. De Vries AM, de Roten Y, Meystre C, Passchier J, Despland JN, Stiefel F. Clinician characteristics, communication, and patient outcome in oncology: a systematic review. Psychooncology. 2014;23(4):375-81.

41. Yuguero Torres O, Esquerda Areste M, Marsal Mora JR, Soler-Gonzalez J. Association between sick leave prescribing practices and physician burnout and empathy. PLoS One. 2015;10(7):e0133379.

42. Visser M, Deliens L, Houttekier D. Physician-related barriers to communication and patient- and family-centred decision-making towards the end of life in intensive care: a systematic review. Crit Care. 2014;18(6):604.

43. von Gunten CF, Ferris FD, Emanuel LL. The patient-physician relationship. Ensuring competency in end-of-life care: communication and relational skills. JAMA. 2000;284(23):3051-7.

44. Embriaco N, Papazian L, Kentish-Barnes N, Pochard F, Azoulay E. Burnout syndrome among critical care healthcare workers. Curr Opin Crit Care. 2007; 13(5):482-8.

45. Great Britain. Parliament: house of commons: health committee. HC 805 end of life care. In: Stationery office; 2015.

46. Michtalik HJ, Yeh HC, Pronovost PJ, Brotman DJ. Impact of attending physician workload on patient care: a survey of hospitalist. JAMA Intern Med. 2013;173(5):375-7.

47. Marine A, Ruotsalainen J, Serra C, Verbeek J. Preventing occupational stress in healthcare workers. Cochrane Database Syst Rev 2006;(4):CD002892.

48. Chen YY, Gordon NH, Connors AF Jr, Garland A, Lai HS, Youngner SJ. Factors associated with two different protocols of do-not-resuscitate orders in a medical ICU*. Crit Care Med. 2014;42(10):2188-96.

49. Liu JM, Lin WC, Chen YM, Wu HW, Yao NS, Chen LT, et al. The status of the do-not-resuscitate order in Chinese clinical trial patients in a cancer Centre. J Med Ethics. 1999:25(4):309-14.

Ready to submit your research? Choose BMC and benefit from:

- fast, convenient online submission

- thorough peer review by experienced researchers in your field

- rapid publication on acceptance

- support for research data, including large and complex data types

- gold Open Access which fosters wider collaboration and increased citations

- maximum visibility for your research: over $100 \mathrm{M}$ website views per year

At $\mathrm{BMC}$, research is always in progress.

Learn more biomedcentral.com/submissions 